\title{
Nanoliter Scale Microbioreactor Array for Quantitative Cell Biology
}

\author{
Philip J. Lee, Paul J. Hung, Vivek M. Rao, Luke P. Lee \\ Department of Bioengineering, Biomolecular Nanotechnology Center, Berkeley \\ Sensor and Actuator Center, University of California, Berkeley, 485 Evans Hall, \\ California 94720-1762; telephone: 510-642-5855; fax: 510-642-5835; \\ e-mail:Iplee@berkeley.edu
}

Received 3 April 2005; accepted 7 September 2005

Published online 28 November 2005 in Wiley InterScience (www.interscience.wiley.com). DOI: 10.1002/bit.20745

\begin{abstract}
A nanoliter scale microbioreactor array was designed for multiplexed quantitative cell biology. An addressable $8 \times 8$ array of three nanoliter chambers was demonstrated for observing the serum response of HeLa human cancer cells in 64 parallel cultures. The individual culture unit was designed with a " $\mathrm{C}$ " shaped ring that effectively decoupled the central cell growth regions from the outer fluid transport channels. The chamber layout mimics physiological tissue conditions by implementing an outer channel for convective "blood" flow that feeds cells through diffusion into the low shear "interstitial" space. The $2 \mu \mathrm{m}$ opening at the base of the " $\mathrm{C}$ " ring established a differential fluidic resistance up to 3 orders of magnitude greater than the fluid transport channel within a single mold microfluidic device. Three-dimensional (3D) finite element simulation were used to predict fluid transport properties based on chamber dimensions and verified experimentally. The microbioreactor array provided a continuous flow culture environment with a Peclet number $(0.02)$ and shear stress $(0.01 \mathrm{~Pa})$ that approximated in vivo tissue conditions without limiting mass transport (10 s nutrient turnover). This microfluidic design overcomes the major problems encountered in multiplexing nanoliter culture environments by enabling uniform cell loading, eliminating shear, and pressure stresses on cultured cells, providing stable control of fluidic addressing, and permitting continuous on-chip optical monitoring. (c) 2005 Wiley Periodicals, Inc.

Keywords: systems biology; microbioreactor array; microfluidics; cell culture; biomimetic
\end{abstract}

\section{INTRODUCTION}

The major challenge of systems biology is to integrate genetic information, protein interactions, and subcellular localization in order to derive functional behaviors (Kitano, 2002). This requires the comprehensive exploration of the experimental parameter space in living organisms. Recent breakthroughs in microfluidic and nanoscale tech-

Correspondence to: L.P. Lee

Philip J. Lee and Paul J. Hung contributed equally to this work.

Contract grant sponsors: NSF Graduate Research Fellowship; NASA research nologies offer tremendous potential for rapid large scale biological analyses in quantitative systems biology (Hood et al., 2004). However, current microscale platforms are unable to characterize the multiple dynamic parameters of living cells in an addressable array. While advances in high throughput technology such as DNA microarrays and yeast two-hybrid screens have yielded a wealth of information on gene expression and protein interactions, large scale cell level studies remain limited. In order to unravel the complexity of biological interactions within living cells, a robust high throughput platform needs to be adopted for cell-based experimentation. To address this concern, a number of groups have developed methods to generate cell patterns using microarray printing technology (Ziauddin and Sabatini, 2001), surface patterning (Anderson et al., 2004), and microwell substrates (Chin et al., 2004). While such methods are suitable for high-density cell patterning, the individual culture volumes are not fluidically isolated and cannot be individually addressed after cell seeding, limiting their ability to control multiple cellular microenvironment parameters.

Microfluidics technology allows the delivery of nanoliter volumes to individual units of an array, making it ideally suited for microenvironment control in a high density cell array (Hung et al., 2005a). In recent years, the development of the soft lithography molding technology has greatly improved the flexibility of designing microscale devices for cell biology research (Walker et al., 2004; Whitesides et al., 2001). This method has been used to demonstrate mammalian cell patterning in an enclosed array (Chiu et al., 2000; Takayama et al., 1999), computerized cell culture (Gu et al., 2004), cellular responses to chemical gradients (Li Jeon et al., 2002), investigation of cellular differentiation (Tourovskaia et al., 2005), tissue bioreactors (Leclerc et al., 2004; Powers et al., 2002a), and observation of dynamic gene expression (Thompson et al., 2004). In order to scale to larger arrays, it is necessary to selectively control fluid transport through the system while maintaining a favorable cell culture environment. Our previous work introduced the concept of a microfluidic cell culture array (Hung et al., 2005a, 2005b), 
but was limited by the inability to reliably perform cell-based experiments in a multiplexed manner. In this study, we addressed these issues by implementing a novel design to mechanically decouple cellular compartments from fluid flow. This was accomplished using two-level soft lithography, which consisted of patterning different channel heights on a single mold such that fluidic resistances ranged over 5 orders of magnitude. By localizing cell growth to predefined areas, fluid transport through the array was isolated from cellular activity. This design was able to demonstrate for the first time an $8 \times 8$ addressable cell microbioreactor array for long term functional studies.

The realization of a microfluidics based cell microarray has many advantages for high throughput biology including greatly reduced sample volumes, inexpensive process automation, precise microenvironment control, and the ability to retain physiologic tissue activity in vitro (Andersson and van den Berg, 2004; Powers et al., 2002b). These functionalities have the potential to provide the field of cellular systems biology with a robust experimental platform for detailed signal analysis from a large number of experimental conditions.

\section{MATERIALS AND METHODS}

\section{Device Fabrication}

The cell microbioreactor array was fabricated using softlithography technology and replicate molding. This process consisted of patterning a polymer mold on a silicon wafer followed by replication with a soft elastomer. SU-8 negative photoresist was used as the mold material. To define the $2 \mu \mathrm{m}$ height features, SU-8 2002 was spin coated on a silicon substrate and desired patterns were photolithographically defined. A second layer of $50 \mu \mathrm{m}$ SU-8 2050 was spin coated over the $2 \mu \mathrm{m}$ SU-8 and photolithographically patterned. Polydimethylsiloxane (PDMS) was prepared with a 10:1 ratio between the silicone base and the curing agents and poured over the developed mold. The mold was degassed in a vacuum chamber for $10 \mathrm{~min}$ before curing in a $70^{\circ} \mathrm{C}$ convective oven for $4 \mathrm{~h}$. Individual devices were separated using a razor blade and the fluidic connection ports punched with an 18 gauge flat tip needle. The device was then irreversibly bonded to a cell culture coverglass after oxygen plasma treatment (PlasmaTherm Etcher, $50 \mathrm{~W}, 2$ Torr, $40 \mathrm{~s}$ ) on both the bottom of the device and the coverglass.

\section{Microfluidic Cell Culture}

All microfabricated components were sterilized with UV light prior to use. Fluidic connections were sterilized with $70 \%$ ethanol and thoroughly rinsed with filtered deionized water prior to use. HeLa cells were suspended from culture dishes at $10^{6}$ cells $/ \mathrm{mL}$ and loaded into the microfluidic culture chambers using a sterile syringe. Loading rate was controlled using a programmable syringe pump. Cells were cultured with continuous perfusion of $\mathrm{CO}_{2}$ independent medium (Gibco, Inc., Grand Island, NY) supplemented with $10 \%$ fetal bovine serum, $4 \mathrm{mM}$ L-glutamine, and $1 \%$ penicillin/streptomycin. During perfusion, the device was placed inside a $37^{\circ} \mathrm{C}$ temperature control oven. Perfusion was controlled with a programmable syringe pump and typically set between 0.2 and $0.4 \mu \mathrm{L} / \mathrm{min}$ through the arrayed device. Cells were cultured for over 2 weeks within the microfluidic array with no loss of viability.

\section{Microfluidic Simulations}

An equivalent circuit model was created from the array geometry to determine fluidic resistances through each culture unit based on laminar Poiseuille flow, and verified with a 3D finite element simulation (FEMLAB 3.1) governed by the Navier-Stokes equation. Three-dimensional models were constructed with a cell growth region of 100,280 , and $500 \mu \mathrm{m}$ in diameter. The "C" shaped ring consisted of a channel $2 \mu \mathrm{m}$ in height and $20 \mu \mathrm{m}$ in width, with a $50 \mu \mathrm{m}$ opening at the mouth for cell loading. All other fluidic compartments were $50 \mu \mathrm{m}$ in height. The outer flow channel was fixed at $50 \mu \mathrm{m}$ in width. Boundary conditions for the simulation were set as no-slip at the surfaces, with fluid velocities of $0.0125,0.0625$, and $0.125 \mu \mathrm{L} / \mathrm{min}$ at the inlet and a pressure of zero at the outlet. The pressure differential across the device was calculated from the simulation results by finding the average inlet and outlet pressures and taking their difference. Shear stress was approximated by finding the velocity gradient $\mathrm{d} u / \mathrm{d} z$ between points 0.10 and $0.11 \mu \mathrm{m}$ above the bottom of the culture well and multiplying the gradient by the viscosity, $\eta$. Peclet number was determined with the equation $U L / D$, where $U$ was the velocity (taken from the center of the cell growth region), $L$ was the characteristic length of the system $(70,160$, and $270 \mu \mathrm{m}$ for the three different ring diameters), and $D$ was the diffusivity (estimated as $1 / 10^{10} \mathrm{~m}^{2} / \mathrm{s}$ for small molecules). Turnover was approximated as the amount of time it took for the concentration in the center of the cell growth region to reach half of the inlet concentration, using a convection/diffusion model assuming no chemical reaction.

\section{Array Characterization}

The fluidic flow profile and cell growth parameters were measured experimentally in the $8 \times 8$ unit array to verify uniformity. The concentration gradient generator was a modified design of a previously described microfluidic diffusive mixer (Li Jeon et al., 2002). Reagent concentrations were determined by measuring the steady state fluorescence intensity of a tracer dye (FITC conjugated dextran, $3 \mathrm{kDa}$, $60 \mu \mathrm{g} / \mathrm{mL}$ ) in each unit of the array at a flow rate of $0.1 \mu \mathrm{L} /$ min for each of two inlets through the microfluidic concentration gradient generator. Cell loading uniformity was calculated from independent loading of each column of the array at $5 \mu \mathrm{L} / \mathrm{min}$ for $5 \mathrm{~min}$ using a solution of $10^{6}$ cells/ $\mathrm{mL}$ in PBS. The growth rate of HeLa cells was calculated based on a simple exponential model: $\mathrm{d} N / \mathrm{d} t=\mu \mathrm{N}$, where $N$ 
was the cell number, $t$ was time (h), and $\mu$ was the specific growth rate $(1 / \mathrm{h})$. The cell number in each unit was counted from a microscope image $(10 \times$ objective) taken every $24 \mathrm{~h}$ for 8 days in two different $64 \mathrm{U}$ arrays with a perfusion rate of $0.4 \mu \mathrm{L} / \mathrm{min}$. The growth rate was calculated with a linear fit of $\ln (N)$ versus $t$ for each microfluidic culture well, giving an average $R^{2}$ value of $0.96 \pm 0.05$. Cell viability was assayed by staining with fluorescein diacetate $(3.0 \mu \mathrm{g} / \mathrm{mL})$ and propidium iodide $(1.0 \mu \mathrm{g} / \mathrm{mL})$ to visualize viable and dead cells, respectively and quantified for each culture unit after 7 days in culture.

\section{Serum Response Analysis}

The linear gradient of serum resulted in FBS concentrations of $0 \%, 1.4 \%, 2.9 \%, 4.3 \%, 5.7 \%, 7.1 \%, 8.6 \%$, and $10 \%$ in the eight rows of the array from two gas-tight inlet syringes containing medium with $0 \%$ serum and $10 \%$ serum pumped at $0.1 \mu \mathrm{L} / \mathrm{min}$. HeLa cells were initially loaded and cultured as described above for $24 \mathrm{~h}$ to seed the array. The cells were then washed with PBS and exposed to trypsin for $30 \mathrm{~min}$ at a flow rate of $1 \mu \mathrm{L} / \mathrm{min}$ to detach the cells from the surface. Serum free medium was introduced for an additional $30 \mathrm{~min}$ at $1 \mu \mathrm{L} / \mathrm{min}$ to remove the trypsin, after which the concentration gradient of serum was exposed to the cell array. Phase contrast micrographs of each culture unit were captured at $t=4,8,12,24,36$, and $48 \mathrm{~h}$ and assayed for cell attachment. Each cell was scored as 0 (not attached), 0.5 (rounded but with clear adhesion fibers), or 1 (spread on culture surface). The attachment factor was calculated as the average cell score in the culture unit. Attachment kinetics were modeled with a simple first order irreversible reaction $[1-F] \longrightarrow[F]$, where $F$ was the fraction of attached cells and $k\left(1 / h^{k}\right)$ was the rate constant, calculated as the linear fit of $-\ln (1-F)$ versus $t$. HeLa cell growth rate at various serum concentrations was determined from data collected at 24, 36, 48, 60, 72, 84, 96, 108, and 121.5 h culture. Fluorescent cell staining was performed inside the microfluidic array. Cells were first fixed in $4 \%$ paraformaldehyde $(5 \mu \mathrm{L} / \mathrm{min}, 15 \mathrm{~min})$, washed with PBS, and permeabilized with $0.5 \%$ Triton $\mathrm{X}$ $100(5 \mu \mathrm{L} / \mathrm{min}, 30 \mathrm{~min})$. The fluorescent stains (Hoescht 3358, $10 \mu \mathrm{g} / \mathrm{mL}$; TRITC-phalloidin, $0.6 \mu \mathrm{g} / \mathrm{mL}$; 5-hexadecanoylamino-fluorescein, $100 \mu \mathrm{g} / \mathrm{mL}$ ) were introduced at $5 \mu \mathrm{L} / \mathrm{min}$ for $20 \mathrm{~min}$ to stain DNA, actin fibers, and cell membranes, respectively.

\section{Statistical Tests}

The uniformity in the array was described using a two-tailed single variance $t$-test. To determine if any trend of row or column position existed for each of the parameters, a regression $t$-test in the form: $t=b / \mathrm{s}_{\mathrm{b}}$ was used, where $b$ was the calculated slope and $s_{b}$ was the standard error of the slope. For the time stability and concentration gradient distribution, a $\chi^{2}$ analysis was performed between the actual results and expected results based on no deviation.

\section{RESULTS}

\section{Microscale Cell Culture Array}

The $2 \mathrm{~cm} \times 2 \mathrm{~cm}$ cell microbioreactor array was designed to perform multiplexed live cell analysis (Fig. 1). The $8 \times 8$ array allowed flow discrimination in two dimensions. In one direction (columns), the channels were individually addressable, enabling loading of various cell populations or introduction of different assay reagents at multiple time points. Flow was restricted to the individual columns by high resistance $2 \mu \mathrm{m}$ height channels between each column. In the perpendicular direction, the channels were connected to the outlets of a concentration gradient generator, providing a different culture condition to the eight rows using only two reagent inlets.

\section{Microfluidic Design}

The microbioreactor array consisted of a network of microfluidic channels and compartments. Due to the low Reynolds number of microfluidic operation $(\operatorname{Re}<0.01)$, the pressure driven flow through the array closely followed the laminar Hagen-Poiseuille relations. In this regime, pressure differential is linearly related to flow rate, allowing a resistive network description of the device design (Fig. 2). The fluidic resistance is defined by channel geometry, and varies with the inverse 4 th power of channel radius. Since the microfluidic chambers consisted of channel heights of 2 and $50 \mu \mathrm{m}$ (channel height ratio of 25), this allowed designing fluidic resistance over 5 orders of magnitude. A 3D finite element model based on the Navier-Stokes equation was performed to simulate the velocity profile through the single culture unit (Fig. 3). Due to the high fluidic resistance from the " $C$ " shaped ring, the average velocity in the cell culture area was predicted to be $\sim 250$-fold less than flow through the outer channel. This resistance ratio was found to be independent of flow rate. By controlling the fluidic resistance ratio, mass transport parameters (e.g., medium turnover, Peclet number) can be optimized without detrimental cellular effects caused by shear stress. The total resistance of flow through the single unit was found to follow the linear relationship: $R=360 \times 10^{4} D+700$, where $D$ was the cell growth area diameter, and $R$ was the fluidic resistance $(\mathrm{Pa})$.

Using established polymer microfabrication technology, cell culture units were created with very well defined, vertical sidewalls (Fig. 4). The individual culture chamber consisted of a $3 \mathrm{~nL}$ central growth volume, a "C" shaped ring with a $2 \mu \mathrm{m}$ opening around its base, and a $50 \mu \mathrm{m}$ outer channel. The mouth of the " $C$ " shape permitted cell loading into the growth area, where the cells were physically retained. The size of the culture area contained $\sim 150$ cells at confluence.

The velocity ratio predicted by the simulations was supported by flow of suspended HeLa cells through a $450 \mu \mathrm{m}$ diameter device. With a cell loading rate of $40 \mathrm{~nL} /$ min through each chamber, cell velocities were observed at $440 \pm 80 \mu \mathrm{m} / \mathrm{s}$ in the flow channel and $0.8 \pm 0.3 \mu \mathrm{m} / \mathrm{s}$ in the 

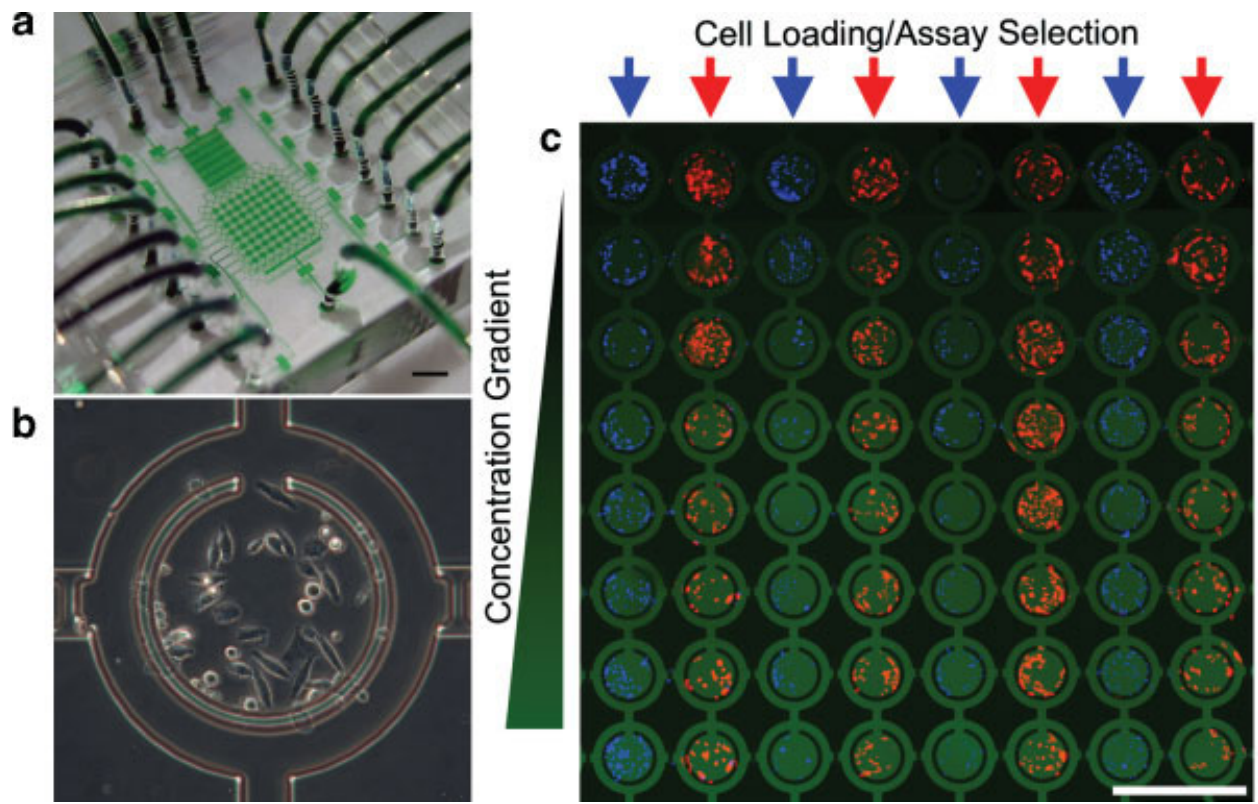

Figure 1. Arrayed cell microbioreactor for quantitative cell biology. a: The microfluidic device containing 64 cell culture units occupied less than $4 \mathrm{~cm}^{2}$ area. A concentration gradient generator was patterned at the top of the array to produce a linear gradient of reagent to each row of the array from only two inlets. Scale bar represents $2 \mathrm{~mm}$. b: HeLa cells cultured in a single well of the array. The " $\mathrm{C}$ " shaped ring design was used to initially load cells from suspension into the $3 \mathrm{~nL}$ central growth area. Continuous perfusion of culture medium allowed the cells to attach to the surface and begin dividing. c: Fluoresecence image of the array demonstrating multiplexed cell assay capability. After 5 days of culture, HeLa cells were fixed and stained with fluorescent dyes for membrane (red) and nucleus (blue) to show column addressability. A concentration gradient of fluorescent dextran solution (green) was then introduced to the array rows. Scale bar represents $1 \mathrm{~mm}$. [Color figure can be seen in the online version of this article, available at www.interscience.wiley.com.]

culture chamber, giving a velocity ratio of 550 . This indicated that the flow rate through the central area was in the range of $50 \mathrm{pL} / \mathrm{min}$. Under these conditions, the time scale of small molecule diffusion through the growth area $(1.7 \mathrm{~min})$ was over fourfold faster than convective transport. Similarly, for a $280 \mu \mathrm{m}$ diameter chamber, the velocity ratio was observed to
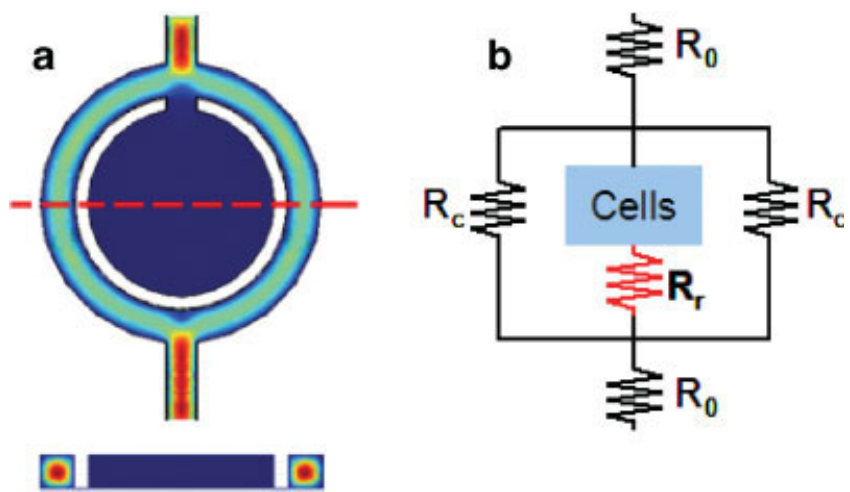

Figure 2. Fluidic resistance of microbioreactor design. a: Theoretical velocity profile and cross section of a device with a $280 \mu \mathrm{m}$ diameter ring, developed from finite element Navier-Stokes simulation. Dark blue indicates low flow, while red reflects fast flow. Convective transport through the center of the well is significantly reduced compared to the outside ring. b: Equivalent circuit model of the microfluidic culture unit design showing resistances from the inlet/outlet channels $\left(R_{o}\right)$, the "C" ring $\left(R_{r}\right)$, and the outer channel $\left(R_{c}\right)$. Due to the small channel size under the " $\mathrm{C}$ "' shaped ring, this fluidic resistance $\left(R_{r}\right)$ dominates the other terms. Different ratios of flow between the inner chamber and outer channel can be designed by altering the ring radius. [Color figure can be seen in the online version of this article, available at www.interscience.wiley.com.] be about 300 . While only $1 / 300$ cells were likely to enter the "C" ring, cell numbers could be controlled from a single cell to a packed bed of cells by varying loading time and density of cell suspension (Fig. 5).

\section{Array Uniformity}

Uniformity of various cell culture parameters were measured for the individual wells in the $64 \mathrm{U}$ array, indicating that there was no statistical significance of array position (Table I). Cell loading uniformity was determined by individual loading of eight columns of an array at $5 \mu \mathrm{L} / \mathrm{min}$ for $5 \mathrm{~min}\left(10^{6}\right.$ cells/ $\mathrm{mL}$ ) resulted in an average of $28.8 \pm 5.5$ cells per chamber. The cell numbers were found to be statistically equivalent to the Poisson distribution $(P>0.99)$, suggesting that each well displayed an equal probability of loading a cell at any given time (Fig. 6). Furthermore, there were no statistical differences between the number of cells loaded in the different rows and columns of the array. The high resistance "C" design was able to provide a more uniform cell distribution (19\% deviation with $0 \%$ of chambers empty) compared with a similar array that did not contain the "C" rings ( $150 \%$ deviation with $47 \%$ of chambers empty).

The two-layer fluidic resistance design concept was also used to improve fluidic uniformity through the $8 \times 8$ array. High resistance $2 \mu \mathrm{m}$ channels were patterned to create regions of dominating resistance to nullify flow perturbations caused by cell bodies or ambient fluctuations. The concentration gradient design produced a linear distribution of a fluorescent tracer molecule through the $64 \mathrm{U}$ of the array with 

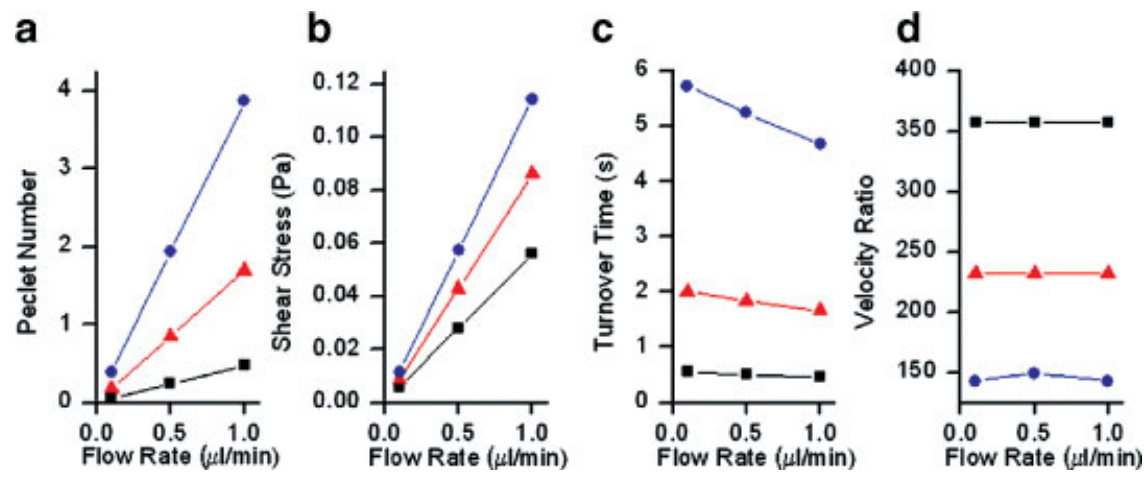

Figure 3. Mass transport properties of the "C" shaped culture unit. Plots were developed from convection-diffusion and Navier-Stokes finite element simulations using a velocity and concentration applied at the inlet for cell culture diameters of $100 \mu \mathrm{m}(\boldsymbol{\square}) 280 \mu \mathrm{m}(\boldsymbol{\Delta})$, and $500 \mu \mathrm{m}(\boldsymbol{O})$. a: Peclet number at the center of the "C" ring. Calculations used a diffusion coefficient value of $1 / 10^{10} \mathrm{~m}^{2} / \mathrm{s}$. b: Shear stress approximated from flow velocity at the center of the "C" ring. c: Turnover time, given as the time for species at the inlet to reach the center of the " $\mathrm{C}$ "-ring. $\mathbf{d}$ : Velocity ratio was given as the ratio of velocity in the middle of the outer channel to the velocity at the center of the " $\mathrm{C}$ " ring. [Color figure can be seen in the online version of this article, available at www. interscience.wiley.com.]

a correlation of $0.994 \pm 0.002$ over $3 \mathrm{~h}$. The gradient was established within $10 \mathrm{~min}$ of flow, and maintained a stable linear gradient over $48 \mathrm{~h}$ (Fig. 7). An $\chi^{2}$ analysis indicated that the concentration profile matched the predicted analytic values and did not deviate over the 48 -h period $(P>0.99)$. HeLa cell growth rates calculated from $64 \mathrm{U}$ of the array indicated a specific growth rate of $0.010 \pm 0.003 / \mathrm{h}$ with no statistical difference as a function of array position. After 1 week of continuous culture, cell viability was $98.5 \pm 2.1 \%$ in each culture well.

\section{Serum Response Quantification}

HeLa cells were cultured in the microfluidic array with fetal bovine serum (FBS) concentrations varying from $0 \%$ to $10 \%$ to observe growth rate and cell attachment response (Fig. 8). Cell growth rate increased linearly between $0 \%$ and $7 \%$ FBS where it reached a plateau. This trend was similar in a microtiter plate with the same medium. Cell attachment kinetics was also found to vary as a function of serum content. A first order reaction model fit the experimental data $(R=0.99 \pm 0.01)$ and the kinetic rate constant was found to vary linearly with serum content $(R=0.99)$. Fluorescent staining of cells cultured in the array for $20 \mathrm{~h}$ indicated that at low serum content, cell morphology was largely rounded with no noticeable actin fibers while at $10 \%$ FBS, cells were clearly spread out with prominent actin filaments at the cell periphery.

\section{DISCUSSION}

There is currently great interest in implementing microfluidic devices for cell based studies to improve experimental throughput (Park and Shuler, 2003). However, scaling microfluidic cell culture environments to a large array format exhibits certain difficulties that have limited widespread adoption of this technology for cell biology studies. Major challenges include ensuring uniform cell loading into the array and long term stability of fluid transport. As each culture unit typically contains a volume of less than $10 \mathrm{~nL}$, uniform array loading is problematic since very small perturbations to fluid flow will significantly disturb cell positions. This inability to control cell localization leads to a state where after prolonged growth, cell mass will alter fluid flow through the array, preventing accurate control of extracellular conditions.

In this study, we describe an arrayed microfluidic platform capable of culture and assay of 64 different cellular microenvironment conditions. Cell loading and microfluidic uniformity was achieved using a unique " $\mathrm{C}$ " shaped design to control flow resistance and to separate cell culture areas from fluid flow regions. Since laminar flow resistance has a 4th power relation to channel geometry, it was possible to engineer parallel flow paths with significantly different flow velocities. This was accomplished by patterning the " $\mathrm{C}$ " ring with a $2 \mu \mathrm{m}$ opening along the base of the structure. This opening was smaller than the cross section of the typical mammalian cell, and prevented loaded cells from flowing out of the chamber. The fluidic resistance can be specified by altering the chamber geometry, allowing the tuning fluid transport properties such as flow velocity, Peclet number, and shear stress independently of pumping conditions.

As the fields of cell biology and tissue engineering continue to mature, there is a growing demand for cell culture methods that are capable of replicating in vivo physiologic conditions. However, the current standardized methods fail to meet these requirements (Table II). The microfabricated platform described in this work was designed to approximate the in vivo tissue environment. For mass transport purposes, the typical tissue unit can be described by three basic parameters: (1) length scale set by the distance between capillary vessels, (2) convective transport of nutrients through the circulation, and (3) diffusive transport of nutrients from vessels to individual cells. The cell culture system that nature has provided is such that a cell is within $100 \mu \mathrm{m}$ of a convective flow (velocity of $\sim 0.5 \mathrm{~mm} / \mathrm{s}$ ) and receives nutrients by diffusion of molecules through a low shear stress interstitial space. Using the 
a

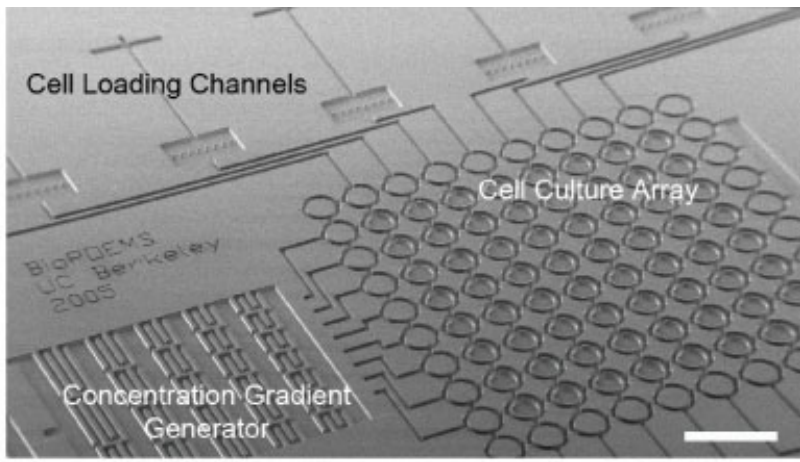

b
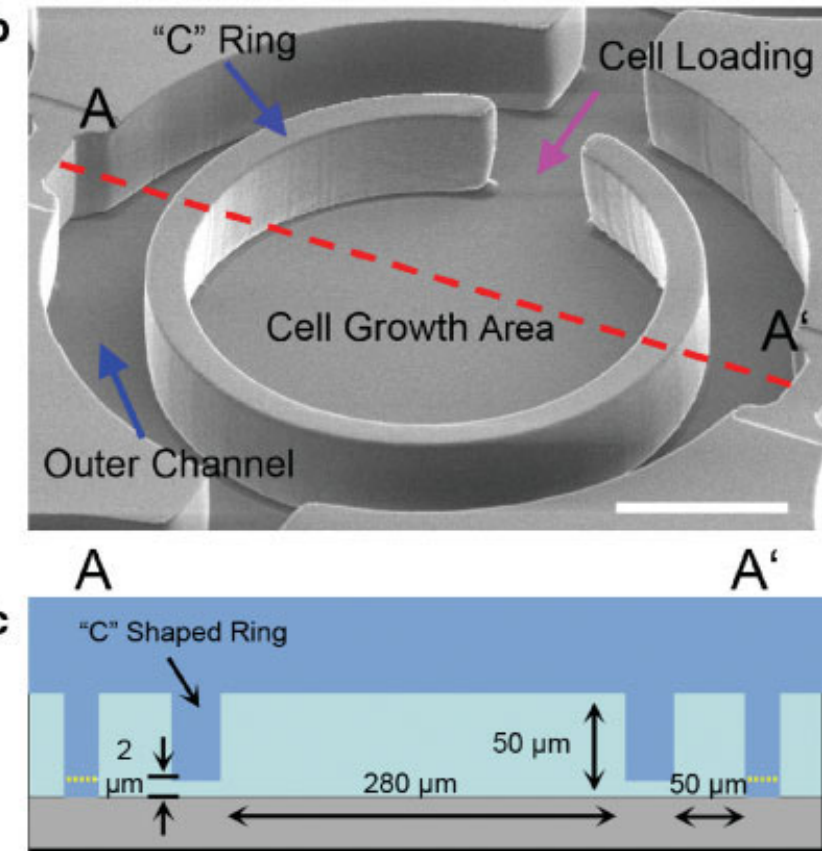

Figure 4. Microfabricated cell culture array. a: SEM image of the PDMS device prior to bonding to a glass microscope slide. Scale bar represents $1 \mathrm{~mm}$. b: SEM image of a single nanoliter-scale culture unit. A central cell growth area is bounded by a "C" shaped ring. Cells from solution are loaded into the mouth of the ring. Since the ring barrier has a $2 \mu \mathrm{m}$ opening along its base, cells are retained in the growth area without limiting nutrient exchange. Scale bar represents $100 \mu \mathrm{m}$. c: Cross sectional view depicting the two layer channel design to control fluidic resistance through the microfabricated device. In this design, a 2 and $50 \mu \mathrm{m}$ channel layer was utilized. [Color figure can be seen in the online version of this article, available at www. interscience.wiley.com.]

Figure 5. Microfluidic flow through the "C" shaped design. a: A 3D finite element simulation of the Navier-Stokes equation was modeled from the culture unit geometry. Due to the large fluidic resistance caused by the $2 \mu \mathrm{m}$ height " $C$ " ring, the fluid velocity was 300 times larger in the outer channel compared with the cell growth area. b: Cell suspension was loaded into the "C" shaped ring at an average flow velocity of $300 \mu \mathrm{m} / \mathrm{s}$. The predicted flow in the growth area was $1 \mu \mathrm{m} / \mathrm{s}$, creating a condition where cells loaded into the ring were nearly stagnant. c: Micrograph taken $1 \mathrm{~s}$ later depicting the loading of a single cell (indicated by arrow) while most cells passed through the outer channel. d: Once the desired loading concentration was reached, the device was washed with PBS, leaving cells only in the central growth areas. [Color figure can be seen in the online version of this article, available at www.interscience.wiley.com.] a
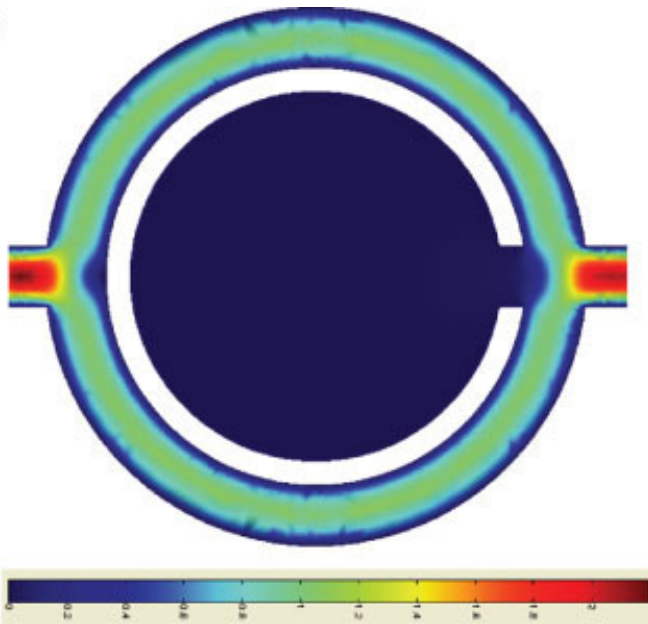

b

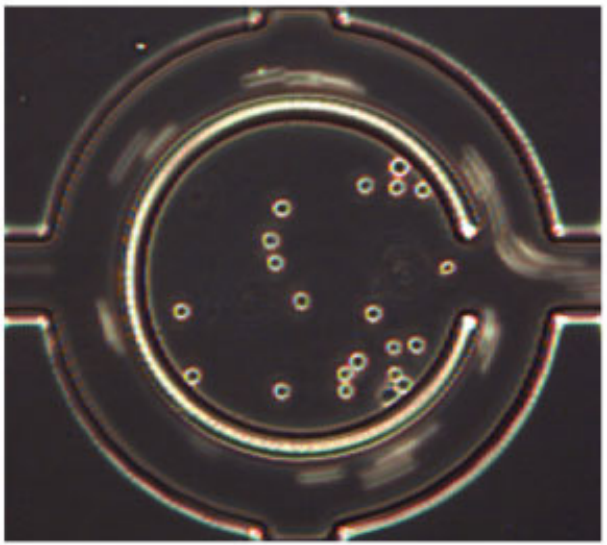

C

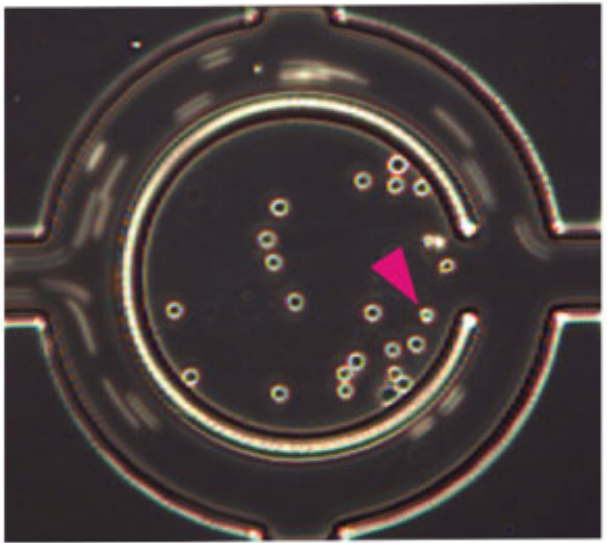

d

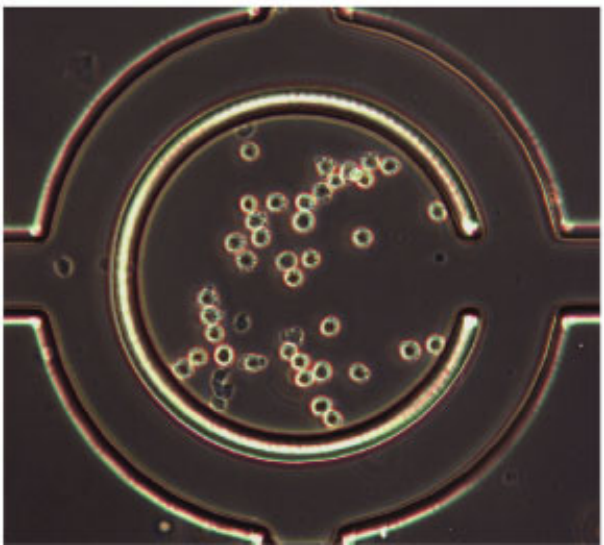


Table I. Uniformity of $8 \times 8$ cell culture array.

\begin{tabular}{lccccc}
\hline Parameter & Avg. \pm SD & Min. value & Max. value & $\begin{array}{c}\text { Row } \\
\text { uniformity }(P)\end{array}$ & $\begin{array}{c}\text { Column } \\
\text { uniformity }(P)\end{array}$ \\
\hline Flow concentration & $0.996 \pm 0.064$ & 0.815 & 1.168 & 0.89 & 0.48 \\
Flow stability & $1.010 \pm 0.048$ & 0.872 & 1.114 & 0.50 & 0.68 \\
Cell loading (cells) & $28.8 \pm 5.5$ & 19 & 42 & 0.89 & 0.68 \\
Growth rate (1/h) & $0.010 \pm 0.003$ & 0.004 & 0.022 & 0.73 & 0.14 \\
Cell viability & $0.985 \pm 0.021$ & 0.925 & 1.000 & 0.25 & 0.63 \\
\hline
\end{tabular}

Various parameters were quantified in the 64-U array to verify uniformity of culture conditions in each row and column of the device. The flow concentration compares the concentration in each well expected for a perfect gradient generator with the observed concentration, using a value of 1 as no deviation. Flow stability was measured from the concentration variation in each well over a $3 \mathrm{~h}$ period of reagent flow through the gradient generator with a value of 1 set as no deviation. Concentration and stability measurements contained an intrinsic $2.9 \%$ measurement error. All data were collected from $64 \mathrm{U}$ of a microbioreactor array. To determine whether there was any trend in these parameters as a function of array position, a $t$-test was used to compare row and column trends, indicating that there was no statistical difference for these parameters $(P>0.10)$.
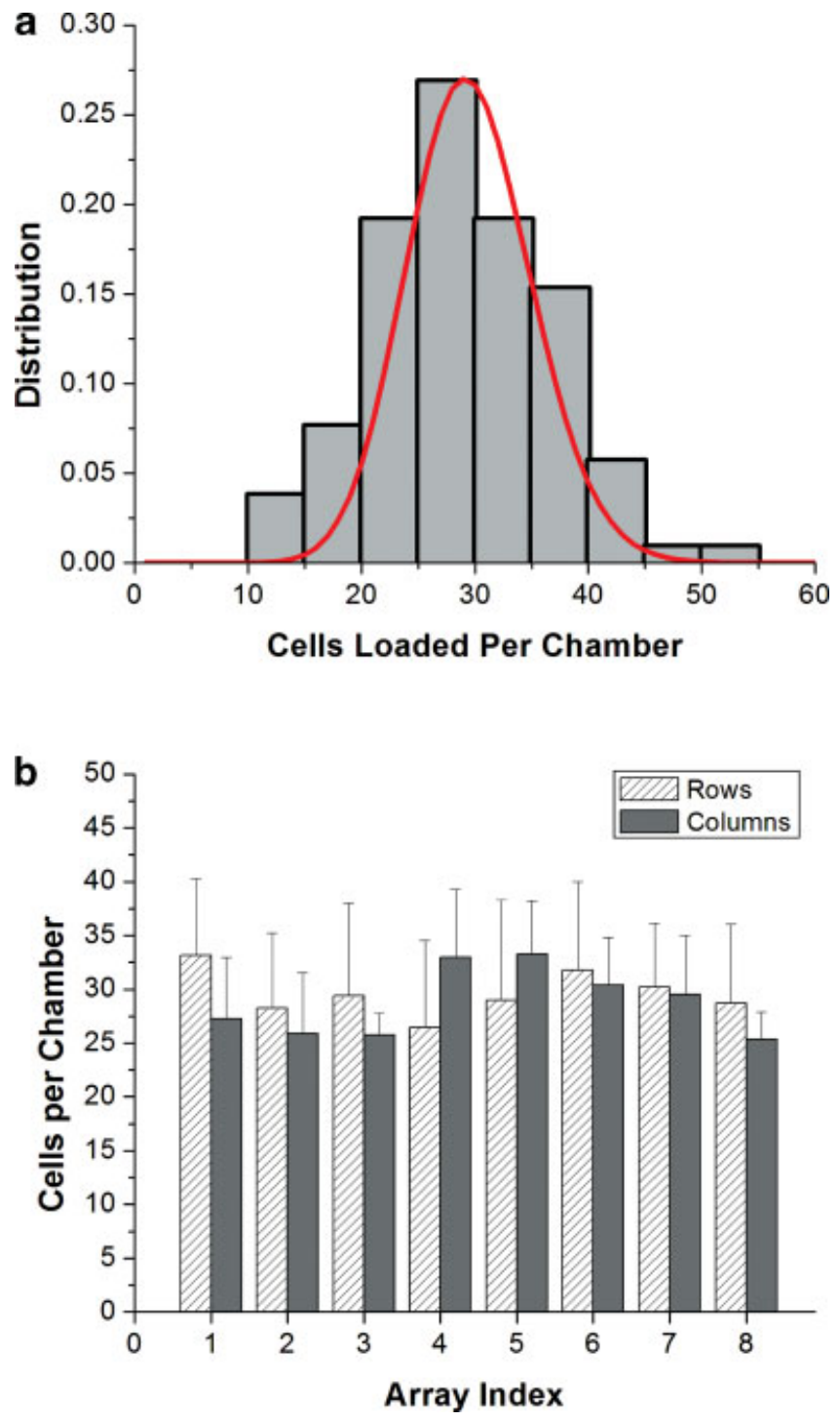

Figure 6. Cell loading uniformity. Suspended HeLa cells were loaded into an $8 \times 8$ array at $5 \mu \mathrm{L} / \mathrm{min}$ for $5 \mathrm{~min}\left(10^{6}\right.$ cells $\left./ \mathrm{mL}\right)$. a: Histogram of cells loaded per well and the expected Poisson distribution (red line) for a stochastic random event. $\mathbf{b}$ : The number of cells loaded was not statistically different as a function of column or row position. [Color figure can be seen in the online version of this article, available at www.interscience.wiley.com.] microfluidic "C" shaped resistive design, we were able to approximate these conditions. The central cell culture chamber represents the "tissue space," with a fast convective "blood" flow through the outer channel, and diffusion dominated transport into the low flow "interstitial space." At the typical perfusion rate of $0.2 \mu \mathrm{L} / \mathrm{min}$ through the array, the Peclet number (ratio of convective transport to diffusive transport) for small proteins $\left(D=1 / 10^{6} \mathrm{~cm}^{2} / \mathrm{s}\right)$ was 0.02 and the surface shear stress was $0.01 \mathrm{~Pa}$. These conditions more closely mimic in vivo interstitial tissue and tumor growth environments (Chary and Jain, 1989; Tzafriri et al., 2005) and may provide an insightful in vitro model, which has been difficult to realize using conventional culture methods $(\mathrm{Ng}$ and Swartz, 2003). The investigation of how these culture parameters affect cell behavior and gene expression poses an interesting question for future work.

The microbioreactor array was molded using PDMS bonded to a glass culture surface. PDMS polymer was selected as the device material based on its proven biocompatibility, gas permeability, optical transparency, and established microfabrication methods. The glass culture surface promoted cell adhesion, directly adapted to inverted microscopy, and was compatible with many surface treatment methods. The cell compatibility of this design was supported by successful culture of SY5Y human neuroblastoma, NIH3T3 fibroblasts, HepG2 hepatocytes, and BAEC primary cells (Fig. 9). HeLa cell viability within the array was found to be $98.5 \%$ after 1 week of continuous culture, suggesting that nutrient limitation, mechanical stress, and material toxicity were not significant factors in this device. Mass transport of nutrients from the flow channel into the cell culture region occurs by diffusion, with a calculated time scale of $\sim 10$ s for small molecules. This rapid turnover allowed culture without the dependence of $\mathrm{CO}_{2}$ gas buffering and humidity control. After prolonged culture times (typically over 1 week), cells would migrate under the " $C$ " ring barrier and grow into the channel regions. Due to the high resistance of the " $C$ " ring, flowing trypsin through the array was able to selectively remove cells growing in the outer channel and maintain cell localization to the central ring (data not shown). 

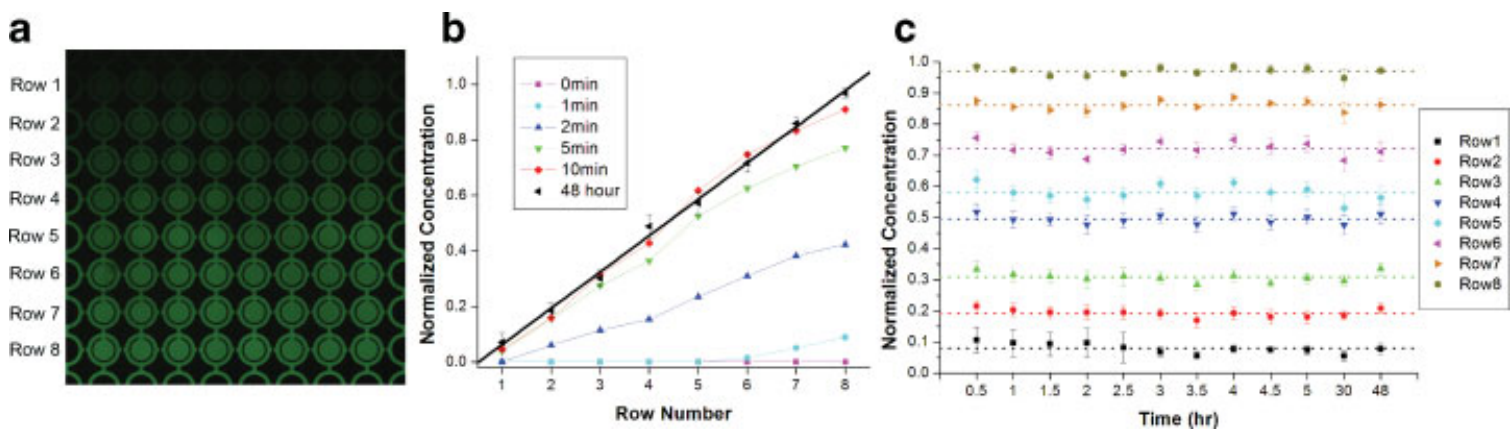

Figure 7. Concentration gradient stability. a: FITC-dextran ( $3 \mathrm{kDa})$ was used to trace gradient concentration in the eight rows of the array. b: Measurement of fluorescence intensity at $1 \mathrm{~min}$ intervals indicated a fully established linear gradient after $10 \mathrm{~min}$. Steady state concentrations are given as mean $\pm \mathrm{SD}$ averaged over $48 \mathrm{~h}$ (linear correlation $=0.997$ ). $\mathbf{c}$ : Concentration uniformity and stability within the " $\mathrm{C}$ " cell growth regions indicate the medium conditions are kept within measurement error over $48 \mathrm{~h}$. Dotted lines indicate $48 \mathrm{~h}$ averages for each row. [Color figure can be seen in the online version of this article, available at www.interscience.wiley.com.]

To demonstrate a quantitative cell assay in the microbioreactor array, we observed HeLa cell growth response to varying FBS concentrations. Cancer cell serum response was one of the earliest and most studied signaling pathways in systems biology (Jones and Kazlauskas, 2000; Schoeberl et al., 2002). Various growth factors isolated from serum have been found to activate the MAP kinase proliferation pathway (Srsen et al., 1999), influence cell attachment, and spreading (Barnes et al., 1980; Sato et al., 1995), and promote the formation of actin fibers (Peck et al., 2002). In the microbioreactor array, 64 cell cultures were simultaneously observed at 8 serum concentrations between $0 \%$ and $10 \%$. The observed trend of cell growth rate was similar to that observed in a microtiter plate. The consistently faster doubling time was possibly due to increased autocrine signaling from the close proximity of cells in the array. Cell attachment to the culture surface was proportional to the number of unattached cells and increased linearly with serum content.

More detailed signal pathway kinetics can be elucidated by following protein phosphorylation and gene expression in real time through the array. Current biological methods that rely on optical detection such as GFP transfection, reporter gene assays, and RNAi screening can be easily adapted to the microfluidic array to generate relevant empirical data for cellular systems biology. For example, an $8 \times 8$ array can be loaded with cells transfected with eight different proteins of interest (in the eight columns) and the expression kinetics monitored under eight growth conditions. It is also possible to modify the array design such that each individual chamber a

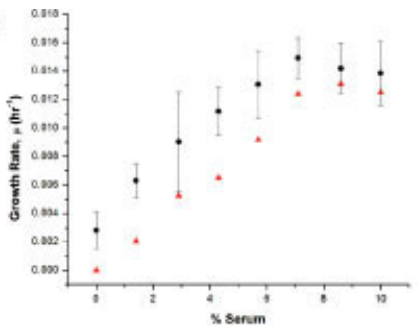

d

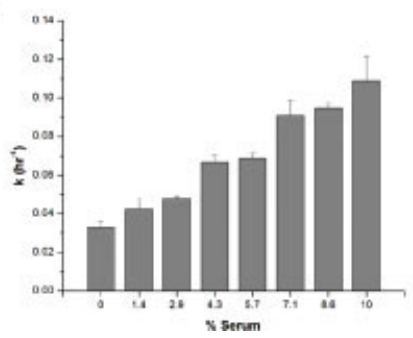

b

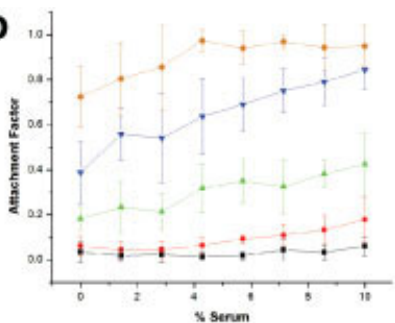

e

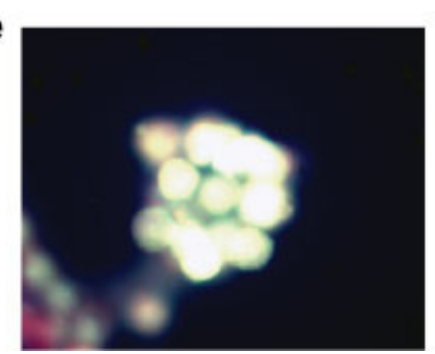

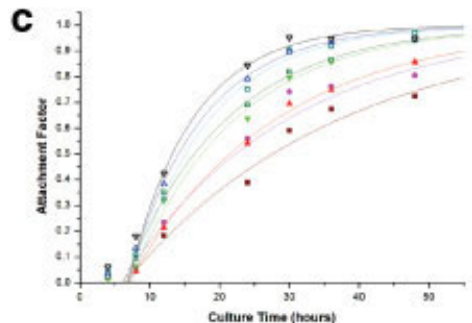

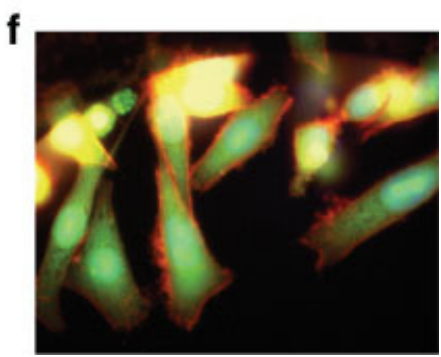

Figure 8. Quantitative measurement of cancer cell serum response in a $64 \mathrm{U}$ array. Using the concentration gradient generator, a linear dose of serum was introduced into the eight rows of the array to monitor HeLa cell response. a: Growth rate of HeLa cells at different serum content for the microbioreactor array (O) and for a microtiter plate $(\boldsymbol{\Delta})$ calculated from an exponential model over 5 days of continuous culture. $\mathbf{b}$ : Cell attachment to the culture surface was assayed by monitoring cell morphology as a function of serum content at $4(\boldsymbol{\square}), 8(\boldsymbol{O}), 12(\boldsymbol{\Delta}), 24(\boldsymbol{\nabla})$, and $48(\boldsymbol{\bullet}) \mathrm{h}$ after loading. c: Using a simple first order reaction model, the mean attachment rate of HeLa cells was fitted for the eight serum conditions $(0 \% \mathbf{\square}, 1.4 \% \mathbf{\boldsymbol { V }}, 2.9 \% \mathbf{\Delta}, 4.3 \% \mathbf{\nabla}, 5.7 \% \square, 7.1 \% \bigcirc, 8.6 \% \mathbf{\Delta}, 10 \%$ $\boldsymbol{\nabla})$. d: Attachment rate constant plotted against serum content. All data represent mean \pm SD of $8 \mathrm{U}$ from a single array. e: Fluorescence image of cell cultured for $20 \mathrm{~h}$ at $0 \%$ serum and (f) $10 \%$ serum. Cells were stained with Hoescht 3358 (blue), TRITC-phalloidin (red), and 5-hexadecanoylamino-fluorescein (green) to stain for DNA, actin fibers, and cell membrane, respectively. [Color figure can be seen in the online version of this article, available at www. interscience.wiley.com.] 
Table II. Physiological parameters of cell culture technologies.

\begin{tabular}{lcccc}
\hline Parameter & Interstitial tissue & Microbioreactor array & 96-well plate & Perfusion CSTR \\
\hline Size $(\mu \mathrm{m})$ & $40-100$ & $40-1000$ & 3,200 & $150,000+$ \\
Volume $(\mathrm{nL})$ & $0.3-4$ & $3-10$ & 50,000 & $1,000,000,000+$ \\
Fluid velocity $(\mathrm{mm} / \mathrm{s})$ & $0.0001-0.7$ & $0.0001-0.8$ & - & $100-1,000$ \\
Peclet number & $\sim 0.1$ & $0.01-10$ & - & $100,000,000$ \\
Shear stress $(\mathrm{Pa})$ & $0-2$ & $0.0001-0.4$ & - & Variable, non-uniform \\
Turnover $(\mathrm{s})$ & $\sim 2$ & $2-250$ & $>10,000$ & $>10,000$ \\
Cell volume ratio & $>0.6$ & $0.4-0.8$ & $<0.05$ & $<0.1$ \\
Reynolds number & $0.00001-0.002$ & $0.00001-0.3$ & - & $>2000$ \\
\hline
\end{tabular}

The microbioreactor array was designed to better approximate the mass transport in vivo tissue environment. The single unit of tissue can be described by the intercapillary distance, which corresponds well with microfabricated features. The "C" shaped design allowed the culture chamber to be divided into two flow regions, a faster convective "blood" flow, and a diffusion dominated "interstitial" space for cell growth. Traditional culture technologies such as microtiter plates and stirred tank bioreactors fail to capture these physiological properties.

has a separate outlet, allowing the collection of fluidic samples for biochemical analysis (e.g., PCR, ELISA, HPLC, mass spectroscopy). Automation of array operation and data collection can be achieved by integrating previously developed microfluidic technology, allowing massively multi- plexed cell level analysis of individual cells (Hong et al., 2004; Thorsen et al., 2002). By enabling biologists with a robust method to control the fluidic environments of an array of cell culture units, the precision and accuracy of quantitative cell experiments will be greatly improved. a

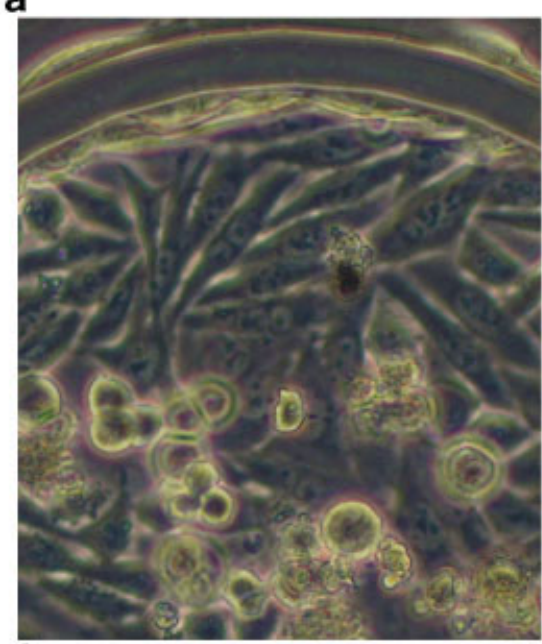

d

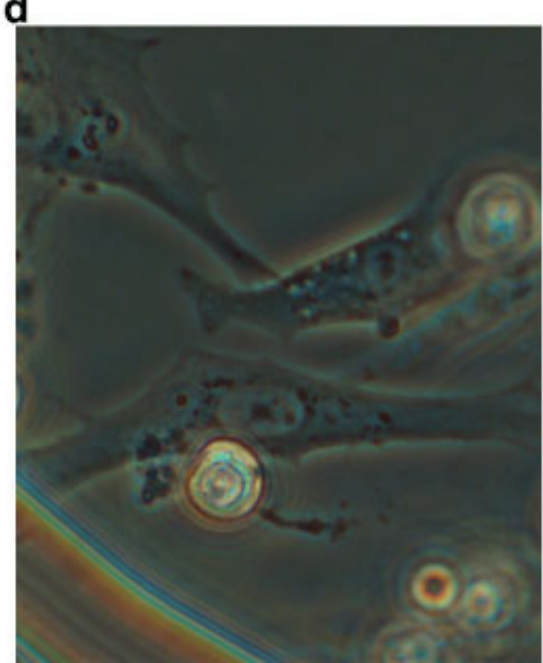

b

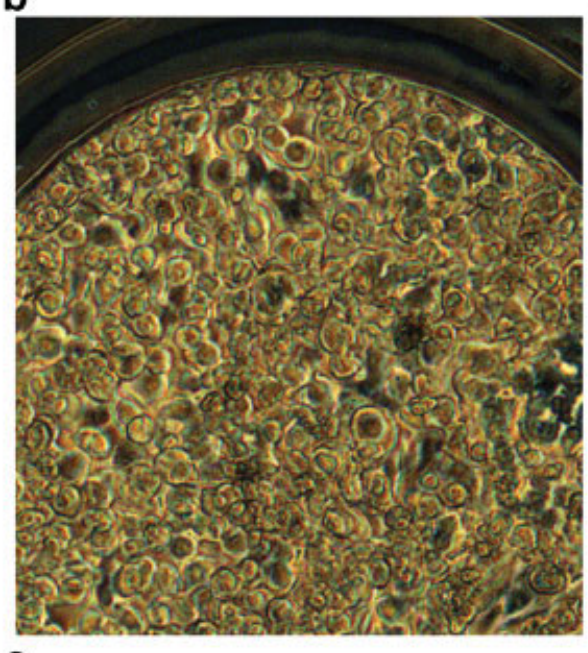

e

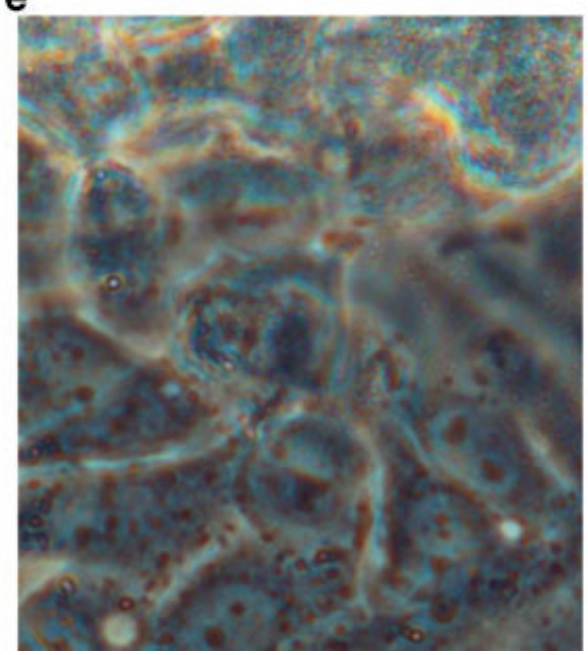

c

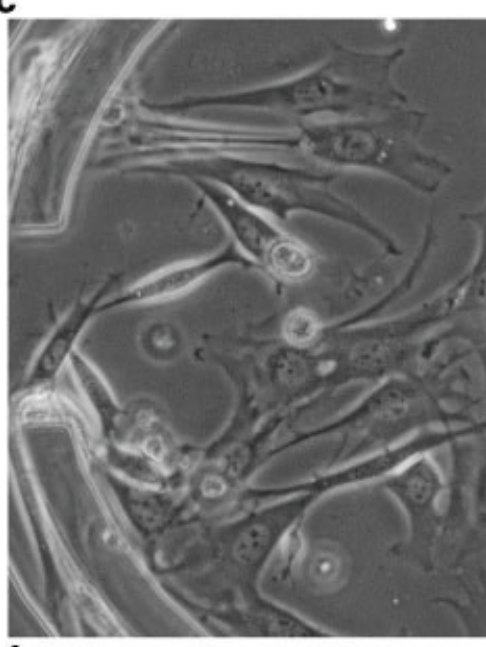

f

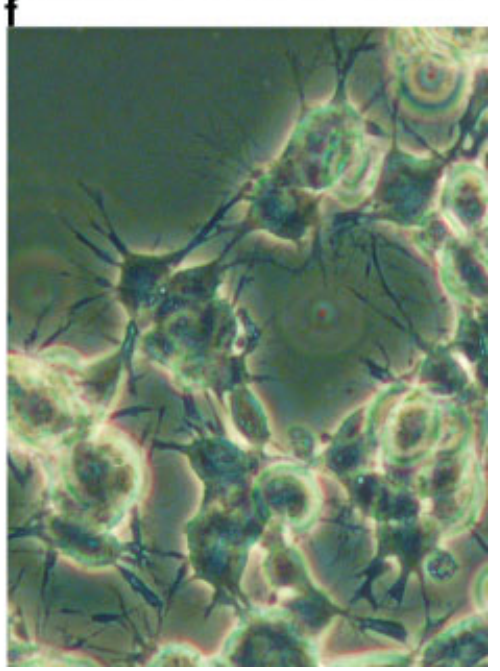

Figure 9. Cells cultured in microfluidic array. Various cell lines were successfully cultured in the "C" shaped microfluidic array, including: a: HeLa, (b) high density HeLa cells after extended perfusion, (c) NIH3T3 fibroblasts, (d) primary bovine endothelial cells, (e) HepG2 hepatocytes, (f) human SY5Y neuroblastoma. [Color figure can be seen in the online version of this article, available at www.interscience.wiley.com.] 
A high throughput microfluidic cell culture platform that offers microenvironment control can prove highly valuable in discovery and validation of cell systems biology. This work proposes a microfluidic method to mimic the mass transport environment of living tissues, enabling controlled delivery of soluble factors to cultured cells in an array format. Other aspects of microenvironment control such as single cell positioning, co-culture of multiple cell types, extracellular matrix patterning, and cell density control are areas of active research.

\section{CONCLUSIONS}

The capabilities discussed in this work lay the foundation for realizing an automated high throughput nanoliter scale quantitative cell analysis platform. The " $\mathrm{C}$ " shaped design of the array units solved many of the interfacing problems associated with addressing arrayed nanoliter cell culture environments. We have demonstrated array uniformity and application of this design for parallel analysis of HeLa cell serum response in a $64 \mathrm{U}$ array. Scale up and automation of the device to perform 96 and 384 well assays is currently in progress. Application of this platform for multiparametric dynamic cell response quantification can potentially close the gap in cell level integration for systems biology.

The authors thank Alex Mok for technical assistance. P.J.L. was supported by a NSF Graduate Research Fellowship and P.J.H. was supported by a NASA research grant.

\section{References}

Anderson DG, Levenberg S, Langer R. 2004. Nanoliter-scale synthesis of arrayed biomaterials and application to human embryonic stem cells. Nat Biotechnol 22(7):863-866.

Andersson H, van den Berg A. 2004. Microfabrication and microfluidics for tissue engineering: State of the art and future opportunities. Lab Chip 4(2):98-103.

Barnes D, Wolfe R, Serrero G, McClure D, Sato G. 1980. Effects of a serum spreading factor on growth and morphology of cells in serum-free medium. J Supramol Struct 14(1):47-63.

Chary SR, Jain RK. 1989. Direct measurement of interstitial convection and diffusion of albumin in normal and neoplastic tissues by fluorescence photobleaching. Proc Natl Acad Sci USA 86(14):5385-5389.

Chin VI, Taupin P, Sanga S, Scheel J, Gage FH, Bhatia SN. 2004. Microfabricated platform for studying stem cell fates. Biotechnol Bioeng 88(3):399-415.

Chiu DT, Jeon NL, Huang S, Kane RS, Wargo CJ, Choi IS, Ingber DE, Whitesides GM. 2000. Patterned deposition of cells and proteins onto surfaces by using three-dimensional microfluidic systems. Proc Natl Acad Sci USA 97(6):2408-2413.

Gu W, Zhu X, Futai N, Cho BS, Takayama S. 2004. Computerized microfluidic cell culture using elastomeric channels and Braille displays. Proc Natl Acad Sci USA 101(45):15861-15866.

Hong JW, Studer V, Hang G, Anderson WF, Quake SR. 2004. A nanoliterscale nucleic acid processor with parallel architecture. Nat Biotechnol 22(4):435-439.

Hood L, Heath JR, Phelps ME, Lin B. 2004. Systems biology and new technologies enable predictive and preventative medicine. Science 306(5696):640-643.
Hung PJ, Lee PJ, Sabounchi P, Lin R, Lee LP. 2005a. Continuous perfusion microfluidic cell culture array for high-throughput cell-based assays. Biotechnol Bioeng 89(1):1-8.

Hung PJ, Lee PJ, Sabounchi P, Aghdam N, Lin R, Lee LP. 2005b. A novel high aspect ratio microfluidic design to provide a stable and uniform microenvironment for cell growth in a high throughput mammalian cell culture array. Lab Chip 5:44-48.

Jones SM, Kazlauskas A. 2000. Connecting signaling and cell cycle progression in growth factor-stimulated cells. Oncogene 19(49):55585567.

Kitano H. 2002. Systems biology: A brief overview. Science 295(5560): $1662-1664$.

Leclerc E, Sakai Y, Fujii T. 2004. Microfluidic PDMS (polydimethylsiloxane) bioreactor for large-scale culture of hepatocytes. Biotechnol Prog 20(3):750-755.

Li Jeon N, Baskaran H, Dertinger SK, Whitesides GM, Van de Water L, Toner M. 2002. Neutrophil chemotaxis in linear and complex gradients of interleukin- 8 formed in a microfabricated device. Nat Biotechnol 20(8):826-830.

$\mathrm{Ng}$ CP, Swartz MA. 2003. Fibroblast alignment under interstitial fluid flow using a novel 3-D tissue culture model. Am J Physiol Heart Circ Physiol 284(5):H1771-H1777.

Park TH, Shuler ML. 2003. Integration of cell culture and microfabrication technology. Biotechnol Prog 19(2):243-253.

Peck JW, Oberst M, Bouker KB, Bowden E, Burbelo PD. 2002. The RhoAbinding protein, rhophilin-2, regulates actin cytoskeleton organization. J Biol Chem 277(46):43924-43932.

Powers MJ, Domansky K, Kaazempur-Mofrad MR, Kalezi A, Capitano A, Upadhyaya A, Kurzawski P, Wack KE, Stolz DB, Kamm R, Griffith LG. 2002a. A microfabricated array bioreactor for perfused 3D liver culture. Biotechnol Bioeng 78(3):257-269.

Powers MJ, Janigian DM, Wack KE, Baker CS, Beer Stolz D, Griffith LG. 2002 b. Functional behavior of primary rat liver cells in a threedimensional perfused microarray bioreactor. Tissue Eng 8(3):499-513.

Sato T, Endo M, Okahata Y. 1995. The influence of serum for spreading of tumor cells on synthetic glycolipid films. J Biomater Sci Polym Ed 7(7): 587-599.

Schoeberl B, Eichler-Jonsson C, Gilles ED, Muller G. 2002. Computational modeling of the dynamics of the MAP kinase cascade activated by surface and internalized EGF receptors. Nat Biotechnol 20(4):370-375.

Srsen V, Kitazawa H, Sugita M, Murofushi H, Bulinski JC, Kishimoto T, Hisanaga S. 1999. Serum-dependent phosphorylation of human MAP4 at Ser696 in cultured mammalian cells. Cell Struct Funct 24(5):321327.

Takayama S, McDonald JC, Ostuni E, Liang MN, Kenis PJ, Ismagilov RF, Whitesides GM. 1999. Patterning cells and their environments using multiple laminar fluid flows in capillary networks. Proc Natl Acad Sci USA 96(10):5545-5548.

Thompson DM, King KR, Wieder KJ, Toner M, Yarmush ML, Jayaraman A. 2004. Dynamic gene expression profiling using a microfabricated living cell array. Anal Chem 76(14):4098-4103.

Thorsen T, Maerk1 SJ, Quake SR. 2002. Microfluidic large-scale integration. Science 298(5593):580-584.

Tourovskaia A, Figueroa-Masot X, Folch A. 2005. Differentiation-on-achip: A microfluidic platform for long-term cell culture studies. Lab Chip 5(1):14-19.

Tzafriri AR, Lerner EI, Flashner-Barak M, Hinchcliffe M, Ratner E, Parnas H. 2005. Mathematical modeling and optimization of drug delivery from intratumorally injected microspheres. Clin Cancer Res 11(2 Pt 1):826834.

Walker GM, Zeringue HC, Beebe DJ. 2004. Microenvironment design considerations for cellular scale studies. Lab Chip 4(2):91-97.

Whitesides GM, Ostuni E, Takayama S, Jiang X, Ingber DE. 2001. Soft lithography in biology and biochemistry. Annu Rev Biomed Eng 3:335373.

Ziauddin J, Sabatini DM. 2001. Microarrays of cells expressing defined cDNAs. Nature 411(6833):107-110. 